\title{
Diagnostıc Performance Of Erythropoetin And Erythropoetin Receptor Levels In Patients With Generalized Anxiety Disorder
}

Ergul Belge Kurutas ( $\sim$ ergulkurutas@gmail.com )

\section{Primary research}

Keywords: Generalized Anxiety Disorder, Erythropoietin, Erythropoietin Receptor

Posted Date: February 27th, 2020

DOl: https://doi.org/10.21203/rs.2.24708/v1

License: (c) (i) This work is licensed under a Creative Commons Attribution 4.0 International License.

Read Full License 


\section{Abstract}

\section{Background}

Generalized anxiety disorder (GAD) is a prevalent psychiatric disorder. Diagnosis of GAD depends on subjective complaints of patients, thus the need for biological markers is constantly emerging. This study aimed, for the first time, to investigate diagnostic value of Erythropoietin (Epo) and its receptor (EpoR) levels in drug-naive patients with GAD.

\section{Methods}

This study included 45 newly diagnosed drug-naive patients with GAD, aged and gender-matched 30 healthy controls. Medical histories were obtained, and physical examinations and laboratory tests were conducted; the Hamilton Anxiety Rating Scale (HAM-A) was also used for all participants. Serum Epo and EpoR levels were measured by ELISA.

\section{Results}

HAM-A score was significantly higher in GAD patients versus the controls $(p<0.05)$. While the levels of Epo in patients with GAD were lower than the control patients, EpoR levels were increased in these patients $(p<0.05)$. Epo/EpoR ratios were significantly lower in the patients with GAD than in the control subjects $(p<0.05)$. A positive significant correlation was observed between the EpoR level and the HAM-A score $(r=0.755, p<0.001)$. However, there was a negative significant correlation between Epo levels and HAM-A score $(r=-0.749, p<0.001)$. ROC analysis revealed both sensitivity and specificity of $100 \%$, respectively, for the presence of anxiety when the serum Epo value was $7.64 \mathrm{ng} / \mathrm{mL}$ (the area under the curve was 1.000) and EpoR value was $0.97 \mathrm{ng} / \mathrm{mL}$ (the area under the curve was 1.000).

\section{Conclusion}

Our findings showed that Epo/EpoR ratio may be an important biomarker for GAD. Epo may be a good choice for GAD treatment.

\section{Introduction}

Generalized anxiety disorder (GAD) is a prevalent and highly disabling mental health condition; however, there is still much to learn with regard to pertinent biomarkers, as well as diagnosis, made more difficult by the marked and common overlap of GAD with affective and anxiety disorders. Recently, intensive research efforts have focused on GAD, applying neuroimaging, genetic, and blood-based approaches toward discovery of pathogenetic and treatment-related biomarkers [1]. Currently studies on biological markers in the human blood such as $\mathrm{G}$ protein-coupled estrogen receptor-1, oxidative stress, testosterone, dehydroepiandrosterone sulfate and cortisol performed to determine peripheral markers [2-5]. Plasma appears to be a rational source for proteomic and metabolomic measurements because it is easily accessible and because several molecules from the brain are transported across the blood-brain barrier 
and reach the circulation. However, drawing inferences from the neurochemical composition of plasma on the processes in the brain is not straightforward [6]. Moreover, only a few studies have been conducted on plasma-based pathogenetic and/or treatment predictors in GAD, indicating the further need to explore such potentially valuable approaches.

Erythropoietin (Epo) is a hematopoietic growth factor that readily crosses the brain blood barrier and is routinely used clinically to treat anemia. This trophic cytokine has not been assessed in the context of anxiety, but recent studies have implicated Epo as having clinical potential [7]. Epo binds to its receptor (EpoR) promoting proliferation and differentiation, neuropsychological function in patients with schizophrenia, multiple sclerosis, depression and bipolar disorder [7, 8]. Epo and EpoR have interesting properties, which make it a candidate for investigation as a novel therapeutic agent in neuropsychiatric diseases. To the best of our knowledge, this is the first study to investigate serum levels of Epo and EpoR in patients with GAD. The present study aimed to evaluate serum Epo and EpoR levels in drug-naive patients who were diagnosed with GAD.

\section{Materials And Methods}

\section{Patients}

The present study included 45 patients aged between 18 and 50 years, who were admitted to psychiatry polyclinic for the first time and newly diagnosed with GAD according to the Diagnostic and Statistical Manual of Mental Disorders, Fourth Edition (DSM-IV). All patients were drug-naive. The control group consisted of age- and gender-matched 30 healthy volunteers. All participants were assessed by a trained clinical psychiatrist. Demographical and clinical characteristics such as gender, age, and co-morbid conditions were recorded. The study protocol was approved by the Scientific Research Ethics Committee of Sutcu Imam University and a detailed informed consent was obtained from each patient and control subject. Exclusion criteria were having endocrine disorders, having autoimmune disorders, being an alcohol and/or substance addict, and having a psychiatric disorder other than GAD or a concomitant physical disease. Demographic data and complete medical history were obtained and physical examination was performed for all participants. The required laboratory tests were performed. The Hamilton Anxiety Rating Scale (HAM-A) was used in all participants $[9,10]$.

\section{Biochemical Analysis}

All blood samples were taken from both groups between 7:30 a.m. to 17:00 p.m, because diurnal variation of Epo or EpoR have been reported in literature [11]. Then, the serum was promptly separated, in a refrigerated centrifuge, and stored at $-20^{\circ} \mathrm{C}$ until analysis. The serum levels of Epo and EpoR were measured by a quantitative sandwich enzyme immunoassay technique (ELISA) using a commercial kit (MyBioSource Company, USA) according to the manufacturer's instruction. 


\section{Statistical Analysis}

Statistical analysis was performed using the Statistical Package for Social Sciences, ver. 22.0 (SPSS Inc., Chicago, IL, USA). A p value of less than 0.05 was considered statistically significant. The normality of continuous variables was assessed using Shapiro-Wilk's W-test. Relationships between the categorical variables were evaluated using the chi-square test. To compare of mean differences for normally distributed continuous variables between the two groups, a Student's t test was used. The Mann-Whitney $\mathrm{U}$ test was used to compare the two groups when the assumption of normality was not fulfilled. While investigating associations of data, correlation coefficients and their significance were calculated with Spearman's test (for non-normally distributed variables) and Pearson's test (for normally distributed variables). A receiver operator characteristics (ROC) curve was plotted in order to find the cut-off point.

\section{Results}

Seventy-five individuals were included in the study. The mean age of the GAD group $(n=45)$ was $36.25 \pm$ 6.02 years, and $28(62.22 \%)$ were female. The mean age of the control group $(n=30)$ was $35.06 \pm 5.56$ years, and $20(66.66 \%)$ were female. No significant differences were found between the groups in terms of age and gender $(p>0.05)$.

As shown in Table 1, HAM-A score of the GAD group was significantly higher than that of the control group $(p<0.05)$. The levels of Epo decreased in patients with GAD compared to control $(p<0.05)$. On the other hand, EpoR levels increased in these patients $(p<0.05)$. Furthermore, the ratio of Epo/EpoR was significantly lower in GAD patients than controls $(p<0.05)$ as shown in Fig. 1. According to Pearson correlation analysis, there was a negative significant correlation between Epo levels and HAM-A score $(r=-0.749, p<0.001)$. However, there was a positive significant correlation between EpoR levels and HAMA score $(r=0.755, p<0.001)$ as shown in Table 2 . 
Table 1

Laboratory and clinical results of patients with GAD and healthy controls.

\begin{tabular}{|lll|}
\hline & $\begin{array}{l}\text { GAD group } \\
\text { mean } \pm \text { SD }\end{array}$ & $\begin{array}{l}\text { Control group } \\
\text { mean } \pm \text { SD }\end{array}$ \\
\hline HAM-A score & $14.06 \pm 3.25$ & $8.27 \pm 2.76^{\star}$ \\
& $(10.79-17.32)$ & $(5.52-11.04)$ \\
\hline Epo $(\mathrm{ng} / \mathrm{mL})$ & $6.69 \pm 0.59$ & $10.82 \pm 1.25^{\star}$ \\
& $(5.26-7.64)$ & $(9.13-14.76)$ \\
\hline EpoR $(\mathrm{ng} / \mathrm{mL})$ & $1.45 \pm 0.16$ & $0.71 \pm 0.11^{\star}$ \\
& $(1.18-1.88)$ & $(0.52-0.97)$ \\
\hline *Significant differences in the levels of Epo and EpoR between patients and control groups $(\mathrm{p}<0.05)$. \\
\hline GAD, Generalized Anxiety Disorder; HAM-A, the Hamilton Anxiety Rating Scale; SD, Standard Deviation; \\
\hline Epo, Erythropoietin; EpoR, Erythropoietin Receptor.
\end{tabular}

Table 2

The results of correlation among HAM-A score, Epo and EpoR

\begin{tabular}{|c|c|c|c|c|}
\hline & & HAM-A score & EpoR & Epo \\
\hline \multirow[t]{2}{*}{ HAM-A score } & $r$ & 1 & $0.755^{\star \star}$ & $-0.749^{* \star}$ \\
\hline & \multicolumn{2}{|l|}{$p$ value } & 0.000 & 0.000 \\
\hline \multirow[t]{2}{*}{ EpoR } & $r$ & $0.755^{\star \star}$ & 1 & $-0.840^{\star \star}$ \\
\hline & $p$ value & 0.000 & & 0.000 \\
\hline \multirow[t]{2}{*}{ Epo } & $r$ & $-0.749^{\star \star}$ & $-0.840^{\star *}$ & 1 \\
\hline & $p$ value & 0.000 & 0.000 & \\
\hline \multicolumn{5}{|c|}{$\begin{array}{l}\star \star \text { Correlation is significant at the } 0.01 \text { level ( } p \text { value). } \\
\text { Pearson Correlation analysis were used. }\end{array}$} \\
\hline \multicolumn{5}{|c|}{$\begin{array}{l}\text { Epo, Erythropoietin ; EpoR, Erythropoietin Receptor; r, The correlation coefficient ; HAM-A, the Hamilton } \\
\text { Anxiety Rating Scale; Epo, Erythropoietin; EpoR, Erythropoietin Receptor. }\end{array}$} \\
\hline
\end{tabular}

A ROC curve was plotted for Epo and EpoR levels. Areas under the curve (AUC) were 1.000 for both Epo and EpoR ( $p$ < 0001). These findings indicate that Epo and EpoR levels are diagnostic. The cut-off point was $7.64 \mathrm{ng} / \mathrm{mL}$ for Epo, and all of the patient group, Epo levels were under the cut-off point. The both sensitivity and specificity of Epo were $100 \%$. For EpoR, the cut-off point was $0.97 \mathrm{ng} / \mathrm{mL}$, and all of the patient group EpoR levels were above the cut-off point. The both sensitivity and specificity of EpoR were 100\% (Figs. 2 and 3). 


\section{Discussion}

To our knowledge this is the first study investigation of Epo and EpoR in patients with GAD. We found that the levels of Epo in patients with GAD were lower than the control patients. However, EpoR levels were increased in these patients. This situation may be due to increased of neuroinflammation in patients with GAD. Camacho recommended that anxious-depression should be considered as a chronic inflammatory phenomenon but the only longitudinal study found the association between GAD and increased C-reactive protein (CRP) level to be attributable to body mass index and medication use [12, 13]. A large cohort study examined the association between anxiety disorders (including GAD, social phobia, PD, and agoraphobia) and inflammation, and the some authors reported elevated CRP levels in male patients with current anxiety disorders and immune dysregulation in patients with a late-onset anxiety disorder [14]. Furthermore, an integrated specificity model emphasizes specific patterns of biological responses to specific psychological states and an anxiety-specific effect on inflammatory activity in clinically anxious individuals has been reported [15-17]. Recent studies have characterized Epo as a potent anti-inflammatory cytokine in chronic inflammatory disorders and infectious diseases [18]. Also, recently, multiple lines of evidence have shown that both endogenous and exogenous Epo has protective roles in CNS injury processes, such as ischemia-reperfusion injury. Although the presence of functional EpoRs in neurons has been challenged, Epo selectively reduced inflammatory and oxidative stress processes associated with brain ischemia, and prevented neuronal apoptosis [19-24].

In our study, decreased levels of Epo/EpoR ratio may due to low Epo levels. Until now, Epo/EpoR ratio has not been reported in patients with GAD. So, we did not compared to our results. This study suggests that efforts aiming to increase either Epo expression or the activation of EpoR in the GAD may be a promising target for GAD treatment, especially in stopping the progression, and potentially reversing the well known behavioral morbidities.

High correlation values constitute an important part of our findings. The correlation coefficient is shown with the ' $r$ ' symbol. A "r value" $\leq 0.35$ represents low or weak correlation, between 0.36 and 0.67 shows moderate correlation, 0.68 to 0.90 shows high correlation, and 0.90 to 1.0 shows very high correlation [25]. We found that a significant negative correlation between HAM-A scores and Epo levels. However, we found that a positive correlation between HAM-A scores and EpoR levels. There are no studies between Epo and HAM-A scores, or between EpoR and HAM-A scores in patients with GAD. So, we did not compared to our results. We believe that a high correlation coefficient forms a basis for the detection of biomarkers.

Identifying diagnostic biomarkers for psychiatric disorders is a rising topic of interest. In some previous studies peripheral markers were proposed for diverse psychiatric disorders. For GAD, Bulut et al. found paraoxonase activity and the AUC value was 0.980 [26]. Furthermore, Güneş et al. showed prolidase was a good biomarker for schizophrenia (AUC:1.000) [27]. Currently, a growing body of evidence exists regarding diagnostic value of several peripheral parameters in psychiatric disorders. From this scope, our 
study shows possible implication for hormon receptor (Epo-EpoR) level as an important research area for detection of peripheral biomarkers.

The limitations of the present study were inclusion of small number of patients and its cross-sectional design. Nevertheless, to our knowledge, there is no study in the literature assessing the serum Epo and EpoR levels in GAD patients; accordingly, this study has the feature of being the first study on this issue. Moreover, all patients were drug-naive. The outcome of the present study is an important in terms of providing data for a treatment approach through target receptors in GAD.

\section{Conclusion}

Our current findings showed that serum Epo/EpoR ratios were significantly lower in the patients with GAD than in the control subjects. The Epo/EpoR ratio may be an important biomarker for GAD. We thought that recombinant erythropoietin may be a good choice for GAD treatment. Our results should be considered preliminary and confirmed by latter studies.

\section{Abbreviations}

GAD: Generalized anxiety disorder; Epo : Erythropoietin; EpoR: Erythropoietin receptor; CRP: C-reactive protein; HAM-A: Hamilton Anxiety Rating Scale; DSM-IV: Diagnostic and Statistical Manual of Mental Disorders, Fourth Edition; ROC: Receiver operator characteristics; AUC: Areas under the curve.

\section{Declarations}

\section{Ethics approval and consent to participat}

Our study was conducted after obtaining approval from the local ethical committee of Sutcu Imam University, Medical Faculty, Kahramanmaras, Turkey. Also, the study was conducted in accordance with the Declaration of Helsinki. As we used routinely generated data with no identifying information, the study carries no harm whatsoever to patients. Data were used only for scientific purposes.

Consent for publication: Not applicable.

\section{Availability of data and material}

All data generated or analyzed during this study are included in this paper.

\section{Competing interests}

The authors declare no conflict of interests regarding the publication of this paper.

Funding: Not applicable

\section{Authors' contributions}


EBK: Intellectual contribution to project design; measurements of Epo and EpoR levels and the interpretation of results; in all aspects of manuscript preparation. Author read and approved the final manuscript.

\section{Acknowledgements}

We gratefully to Psychiatrist Dr. Ebru Findikli for key role in physical examination of patients and in the obtain of samples and perform this study's medical record.

\section{Authors' information}

${ }^{1}$ Sutcu Imam University, Faculty of Medicine, Department of Medical Biochemistry, 46050, Avsar Campus, Kahramanmaras,Turkey

\section{References}

1. Maron E, Nutt D. Biological markers of generalized anxiety disorder. Dialogues Clin Neurosci 2017;19:147-158

2. Fındıklı E, Camkurt MA, Karaaslan MF, Kurutas EB, Altun H, İzci F, Fındıklı HA, Kardas S. Serum levels of $\mathrm{G}$ protein-coupled estrogen receptor 1 (GPER1) in drug-naive patients with generalized anxiety disorder. Psychiatry Res 2016;244:312-316.

3. Fındıklı E, Camkurt MA, İzci F, Karaaslan MF, Fındıklı HA, Sümer P, Kurutaş EB. The diagnostic value of malondialdehyde, superoxide dismutase and catalase activity in drug naïve, first episode, nonsmoker generalized anxiety disorder patients. Clin Psychopharmacol Neurosci. 2018;16:88-94.

4. Camkurt MA, Fındıklı E, İzci F, Kurutaş EB, Tuman TC. Evaluation of malondialdehyde, superoxide dismutase and catalase activity and their diagnostic value in drug naïve, first episode, non-smoker major depression patients and healthy controls. Psychiatry Res 2016;238:81-85.

5. Bulut SD, Bulut S, Gundogmus AG, Aydemir C. Serum DHEA-S, testosterone and cortisol levels in female patients with schizophrenia. Endocr Metab Immune Disord Drug Targets 2018;18:348-354.

6. Bandelow B, Baldwin D, Abelli M, Bolea-Alamanac B, Bourin M, Chamberlain SR, Cinosi E, Davies S, Domschke K, Fineberg N, Grünblatt E, Jarema M, Kim YK, Maron E, Masdrakis V, Mikova O, Nutt D, Pallanti S, Pini S, Ströhle A, Thibaut F, Vaghi MM, Won E, Wedekind D, Wichniak A, Woolley J, Zwanzger P, Riederer P. Biological markers for anxiety disorders, OCD and PTSD: A consensus statement. Part II: Neurochemistry, neurophysiology and neurocognition. World J Biol Psychiatry 2017; 18:162-214.

7. Osborn M, Rustom N, Clarke M, Litteljohn D, Rudyk C, Anisman H, Hayley S. Antidepressant-like effects of erythropoietin: a focus on behavioural and hippocampal processes. PLoS One 2013;8:e72813.

8. Inkster B, Zai G, Lewis G, Miskowiak KW. GSK3ß: a plausible mechanism of cognitive and hippocampal changes induced by erythropoietin treatment in mood disorders? Transl Psychiatry 
2018;8:216.

9. Hamilton M. The assessment of anxiety states by rating. Br J Med Psychol 1959; 32:50-55.

10. Yazici MK, Demir B, Tanriverdi N, Karaagaoglu E, Yolac P. Hamilton anxiety rating scale: interrater reliabilty and validity study. Turkish J Psychiatry 1998;9: 114-117.

11. Cahan C, Decker MJ, Arnold JL, Washington LH, Veldhuis JD, Goldwasser E, Strohl KP. Diurnal variations in serum erythropoietin levels in healthy subjects and sleep apnea patients. J Appl Physiol 1992;72:2112-2117.

12. Camacho A. Is anxious-depression an inflammatory state? Med Hypotheses 2013;81:577-581.

13. Copeland WE, Shanahan L, Worthman C, Angold A, Costello EJ. Generalized anxiety and C-reactive protein levels: a prospective, longitudinal analysis. Psychol Med 2012;42:2641-2650.

14. Vogelzangs N, Beekman AT, de Jonge P, Penninx BW. Anxiety disorders and inflammation in a large adult cohort. Transl Psychiatry 2013;3:e249.

15. Kemeny ME. An interdisciplinary research model to investigate psychosocial cofactors in disease: Application to HIV-1 pathogenesis. Brain Behav Immun 2003;17: 62-72.

16. Moons WG, Eisenberger NI, Taylor SE. Anger and fear responses to stress have different biological profiles. Brain Behav Immun 2010;24: 215-219.

17. O'Donovan A, Hughes BM, Slavich GM, Lynch L, Cronin MT, O'Farrelly C, Malone KM. Clinical anxiety, cortisol and interleukin-6: evidence for specificity in emotion-biology relationships. Brain Behav Immun 2010;24:1074-1077.

18. Steiner J, Bogerts B, Sarnyai Z, Walter M, Gos T, Bernstein HG, Myint AM. Bridging the gap between the immune and glutamate hypotheses of schizophrenia and major depression: Potential role of glial NMDA receptor modulators and impaired blood-brain barrier integrity. World J Biol Psychiatry 2012;13:482-492.

19. Iliana S, Yuneidys M, Jorge DG, Nelvis S, Janette C, Adriana M, Yanier N, Julio CG. Recombinant human erythropoietin as a neuroprotective therapy in brain ischemia. Pharmacol Online 2008;25:223-229.

20. Sirén AL, Knerlich F, Poser W, Gleiter CH, Bruck W, Ehrenreich H. Erythropoietin and erythropoietin receptor in human ischemic/hypoxic brain. Acta Neuropathol 2001;101:271-276.

21. Sirén AL, Radyushkin K, Boretius S, Kämmer D, Riechers CC, Natt O, Sargin D, Watanabe T, Sperling S, Michaelis T, Price J, Meyer B, Frahm J, Ehrenreich H. Global brain atrophy after unilateral parietal lesion and its prevention by erythropoietin. Brain 2006;129:480-489.

22. Villa P, Bigini P, Mennini T, Agnello D, Laragione T, Cagnotto A, Viviani B, Marinovich $M$, Cerami A, Coleman TR, Brines M, Ghezzi P. Erythropoietin selectively attenuates cytokine production and inflammation in cerebral ischemia by targeting neuronal apoptosis. J Exp Med 2003;198:971-975.

23. Yu YP, Xu QQ, Zhang Q, Zhang WP, Zhang LH, Wei EQ. Intranasal recombinant human erythropoietin protects rats against focal cerebral ischemia. Neurosci Lett 2005;387:5-10. 
24. Zhang F, Signore AP, Zhou Z, Wang S, Cao G, Chen J. Erythropoietin protects CA1 neurons against global cerebral ischemia in rat: potential signaling mechanisms. J Neurosci Res 2006;83:12411251.

25. Taylor R. Interpretation of the correlation coefficient: a basic review. J Diag Med Sonography 1990;6:35-39.

26. Bulut M, Selek S, Bez Y, Karababa IF, Kaya MC, Gunes M, Emhan A, Aksoy N, Sir A. Reduced PON1 enzymatic activity and increased lipid hydroperoxide levels that point out oxidative stress in generalized anxiety disorder. J Affect Disord 2013;150: 829-833.

27. Güneş $M$, Bulut $M$, Demir S, İbiloğlu AO, Kaya MC, Atlı A, Kaplan I, Camkurt MA, Sir A. Diagnostic performance of increased prolidase activity in schizophrenia. Neurosci Lett 2016;613:36-40.

\section{Figures}

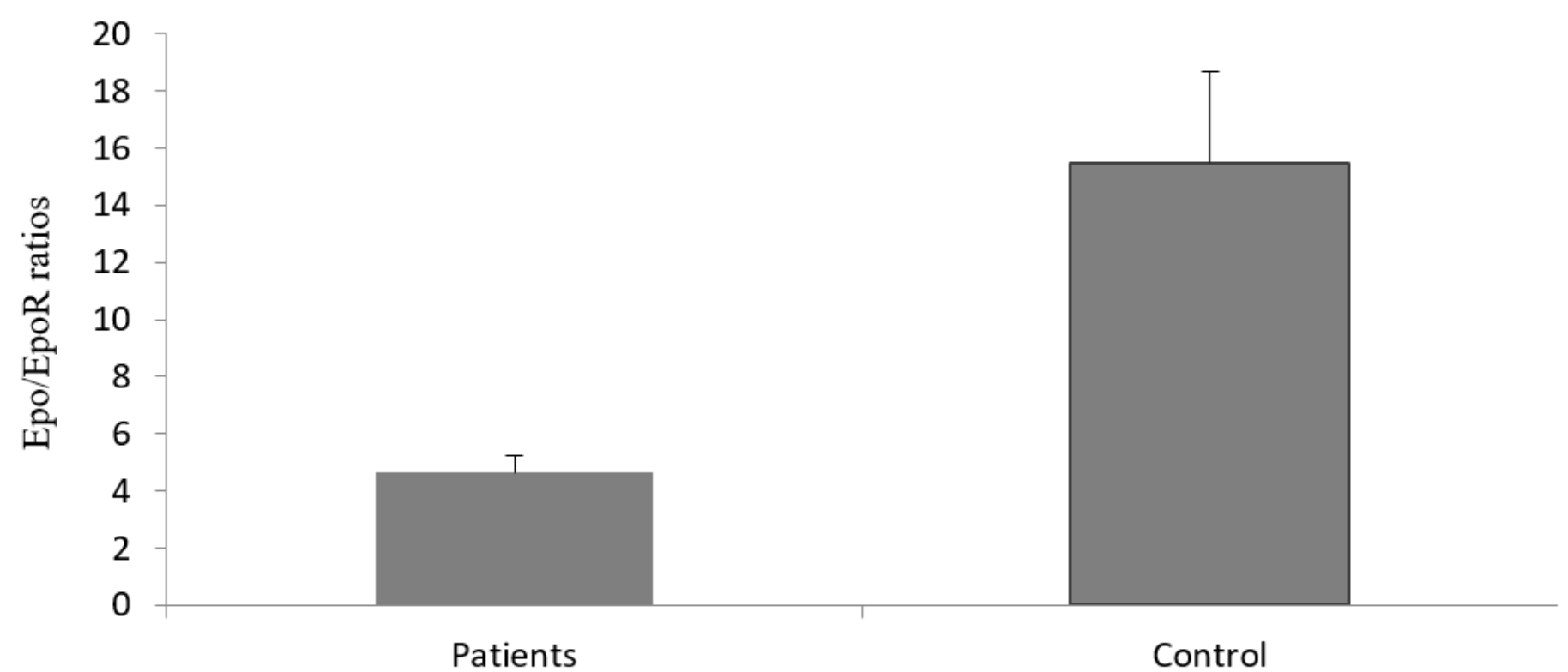

\section{Figure 1}

Epo/EpoR ratios in patients with GAD and control groups. Epo/EpoR ratios were significantly lower in the patients with GAD than in the control subjects $(\mathrm{p}<0.05)$. Epo, Erythropoietin; EpoR, Erythropoietin receptor; GAD, Generalized Anxiety Disorder. 


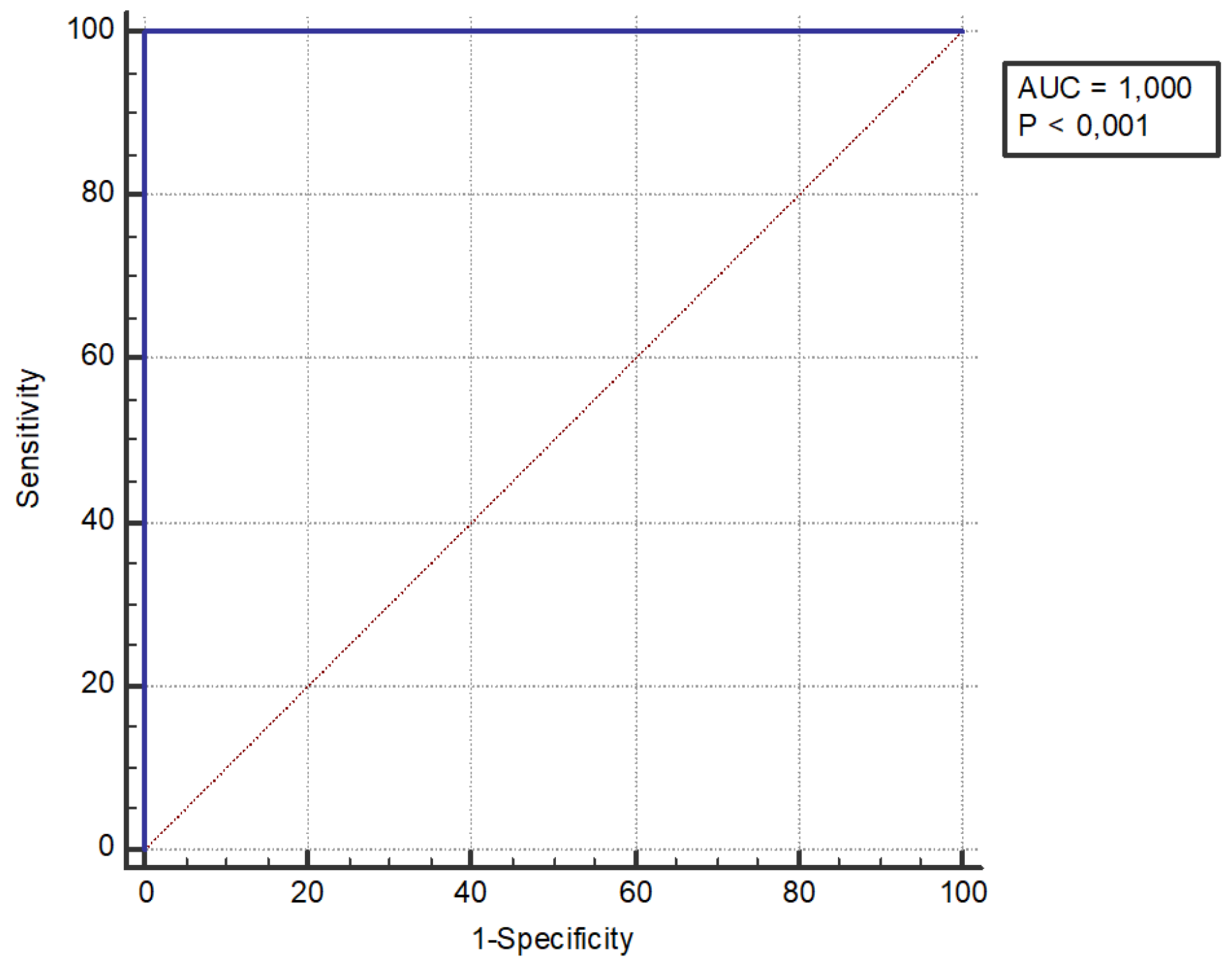

Figure 2

Receiver operating characteristic (ROC) curve analyses of Erythropoietin (Epo). The area under the ROC curve was determined as 1.000. This curve combines the information of the Area Under Curve (AUC) is a measure of the overall discriminative power of Epo level. 


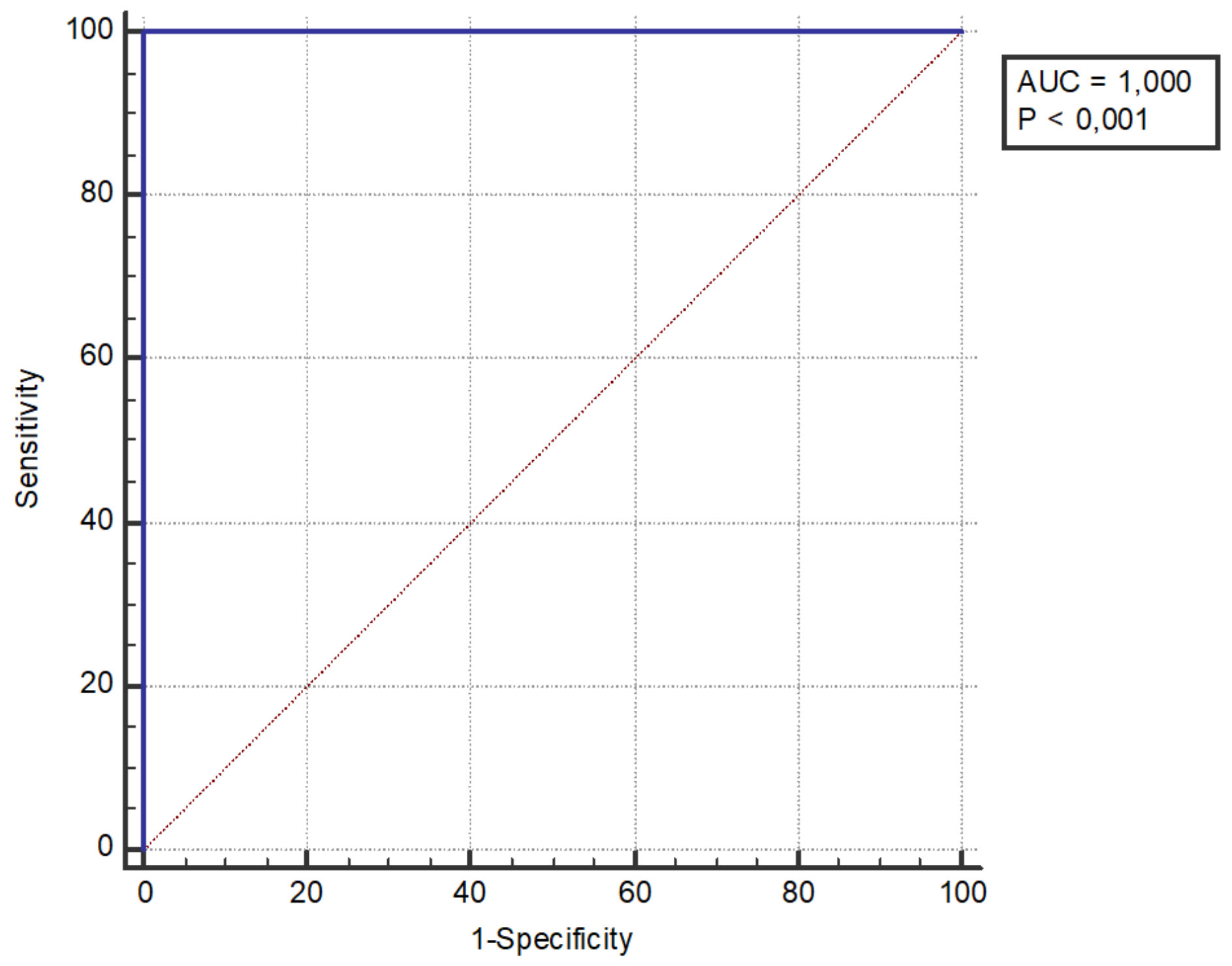

Figure 3

Receiver operating characteristic (ROC) curve analyses of Erythropoietin Receptor (EpoR). The area under the ROC curve was determined as 1.000. This curve combines the information of the Area Under Curve (AUC) is a measure of the overall discriminative power of EpoR level. 